\title{
El antiguo campamento minero de Potrerillos: memoria, patrimonialización y ¿turismo? en la región de Atacama, Chile
}

\author{
Mauricio Lorca | Instituto de Investigaciones en Ciencias Sociales y Educación, Universidad de Atacama \\ URL de la contribución <www.iaph.es/revistaph/index.php/revistaph/article/view/4457>
}

El yacimiento de Potrerillos se ubica al norte de la región de Atacama, en la comuna de Diego de Almagro, a $2.800 \mathrm{msnm}$. Hasta la primera década del siglo XX, el yacimiento fue explotado de forma tradicional, para en 1916 pasar a manos de la estadounidense Anaconda Copper Company. El asentamiento minero-industrial de Potrerillos fue fundado en 1919 y en 1927 comenzó a operar a plena capacidad inaugurando la gran minería del cobre en la región, convirtiéndose rápidamente en el motor económico de la zona.

Alrededor de Potrerillos se generó una compleja ocupación del territorio. Por un lado, se creó una importante red productiva: en el borde costero, en Barquitos, a $8 \mathrm{~km}$ al sur del puerto de Chañaral, se construyó una planta de sulfuros y otra de lixiviación, un puerto de embarque y una planta termoeléctrica y un ferrocarril unió ese complejo a Potrerillos. Asociado a ese sistema industrial, se erigió un asentamiento urbano que llegó a albergar, entre trabajadores y sus familias, unas 10.000 personas;

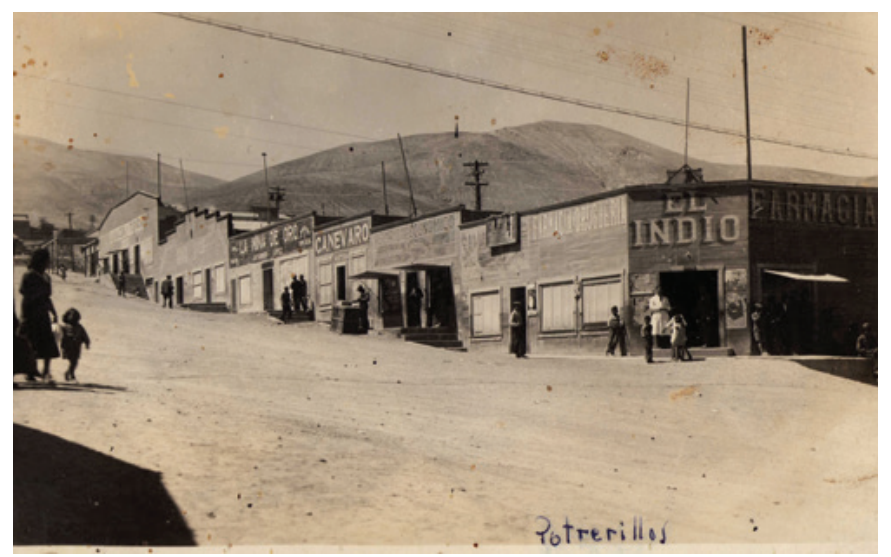

Potrerillos, calle Comercio (ca. 1930) | foto colección fotográfica del Museo Regional de Atacama además de contar con viviendas y edificios de equipamiento, el lugar fue dotado de plaza, escuela, iglesia, hospital, cuartel de policía, instalaciones administrativas, hotel, jardín infantil, teatro, un estadio de fútbol y canchas de tenis y golf (ALVEAR, 1975). En otras palabras, Potrerillos es un fiel representante de company town entendido como "una alternativa completa a la ciudad histórica, no tanto a causa de las formas en las que se estructura, cuanto por el hecho de asumir una única y nueva función, la fábrica, sin otros fines que los de máxima eficiencia productiva, creando un sistema monocultural sin rupturas socioeconómicas" (DAL CO 1975, en GARCÉS, 2003: 132).

En 1997 Potrerillos fue declarado zona saturada de contaminación por la Comisión Nacional del Medio Ambiente (CONAMA) y, en el año 2000, erradicado. Es decir, su población tuvo que trasladarse a distintas ciudades de la región y el país. Desde entonces el asentamiento pasó a ser un recinto industrial de su propietaria, la Corporación Nacional del Cobre (CODELCO), y sus estructuras habitacionales comenzaron a ser progresivamente inhabilitadas, redestinando esos espacios para nuevos emprendimientos mineros. A pesar de esto, la empresa permite que el ex campamento sea visitado de manera restringida por sus antiguos pobladores en dos fechas del calendario católico: el 16 de julio, día de la Virgen del Carmen, y el 1 de noviembre, día de Todos los Santos.

A partir del año 2010, los antiguos habitantes del lugar comenzaron a contactarse por medio de Facebook activando una red de emociones cuya trama se conforma a partir de los sentimientos compartidos, la solidaridad y el orgullo asociados a la experiencia de haber habitado un enclave minero en medio del desierto (RANA; 


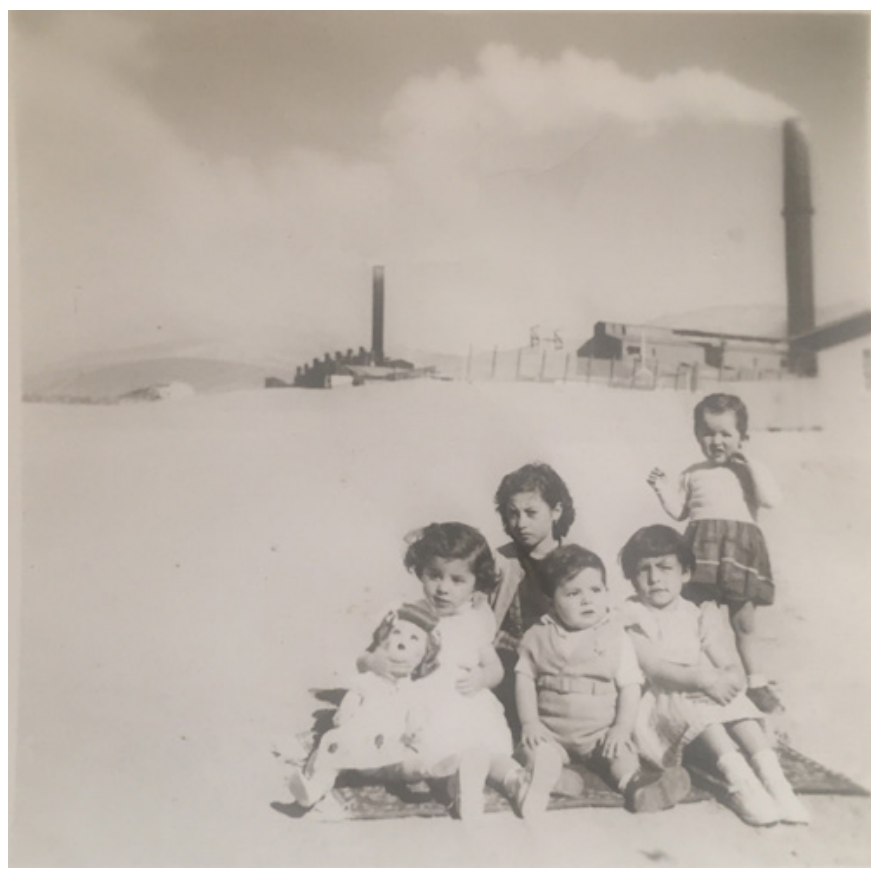

Niños posando delante de la fundición del asentamiento minero de Potrerillos (ca. 1956) | foto Javier Arancibia, fuente www.enterreno.com

WILLEMSEN; DIBBITS, 2017). Al mismo tiempo, el grupo empezó a organizarse para que el lugar sea protegido oficialmente y así mantener vigente su memoria. El año 2012, después de haber logrado el compromiso de la empresa para conservar algunas zonas representativas del antiguo campamento y haber recolectado cientos de firmas electrónicamente, se solicitó formalmente al organismo técnico encargado de la protección y la tuición del patrimonio cultural y natural del país -el Consejo de Monumentos Nacionales, CMN- que Potrerillos sea declarado monumento nacional histórico. Sin embargo, hasta la fecha se desconoce el estado de esa solicitud.

Las dinámicas de patrimonialización que se observan alrededor del ex campamento de Potrerillos confirman tres hechos: primero, que la minería es uno de los principales sectores de la producción industrial en ser activados patrimonialmente; segundo, que el reconocimiento y la valoración simbólica de este tipo de bienes pueden emerger y ser conducidas por la sociedad civil organizada, convirtiéndose en parte fundamental de su memoria y acervo cultural y, tercero, la tensión que este tipo de procesos suscita entre los intereses sociales y los empresariales. En este caso, entre las asociaciones patrimoniales y la Corporación Nacional del Cobre.

Pero, cabe preguntarse cuál es la función, más allá de lo simbólico, que cumple o puede cumplir la activación de Potrerillos. Es cierto, la principal misión del patrimonio es erigirse como referente simbólico del grupo que le activa pero también puede ejercer funciones económicas cuando se asocia a la actividad turística. En efecto, como se ha indicado con anterioridad (LORCA, 2015), el área en la que se inserta Potrerillos, la provincia de Chañaral, tiene un perfil mono productor históricamente orientado a la explotación minera, lo que redunda en la necesidad de diversificar su matriz productiva. Sin embargo, el turismo emerge como una posibilidad lejana debido a lo geográficamente marginal del territorio -Potrerillos se ubica a $219 \mathrm{~km}$ del principal centro urbano de la región, Copiapó, la capital regional, y a casi 250 km del aeropuerto más cercano- y el poco reconocimiento e integración de sus atractivos al mercado turístico nacional. Además, la infraestructura hotelera, la gastronomía y los operadores turísticos en la zona son escasos y la red de transporte que lo une al resto de la región es deficiente. Esto, sin duda, atenta contra la posibilidad de que exista un flujo de visitantes permanente, entorpeciendo la viabilidad y la sustentabilidad de cualquier inversión y desarrollo de infraestructura turística en el área de interés.

Tal vez esto explica en parte por qué se ha dilatado el pronunciamiento de la institucionalidad patrimonial acerca del destino de Potrerillos, condenándolo de alguna manera al ámbito de la memoria y de las colecciones fotográficas que lo retrataron mientras operó. 
a debate ¿Hay patrimonio sin comunidad? Despoblamiento, turistificación y patrimonio cultural

| coordina Jaime Jover Báez

\section{BIBLIOGRAFÍA}

- AlVEAR, J. (1975) Nuestro cobre: Chuquicamata, El Salvador, Potrerillos, El Teniente, Enami, Mantos Blancos y Andina. Santiago de Chile: Editorial Lastra, 1975

- GARCÉS, E. (2003) Las ciudades del cobre: Del campamento de montaña al hotel minero como variaciones de la company town. EURE, vol. 29, n. ${ }^{\circ} 88,2003$, pp. 131148 <https://dx.doi.org/10.4067/S0250-71612003008800006> [Consulta: 01/08/2019]

- LORCA, M. (2016) Proyecciones del legado minero-industrial en la provincia de Chañaral, región de Atacama, Chile. Diálogo Andino, n. ${ }^{\circ}$ 51, 2016, pp. 45-56 <https://dx.doi.org/10.4067/ s0719-26812016000300045> [Consulta: 1/8/2019]

- RANA, J.; WILLEMSEN, M.; DIBBITS, H. C. (2017) Moved by the tears of others: Emotion networking in the heritage sphere. International Journal of Heritage Studies, vol. 23, n. ${ }^{0}$ 10, 2017, pp. 977-988 <https://doi.org/10.1080/13527258.201

7.1362581> [Consulta: 01/08/2019] 